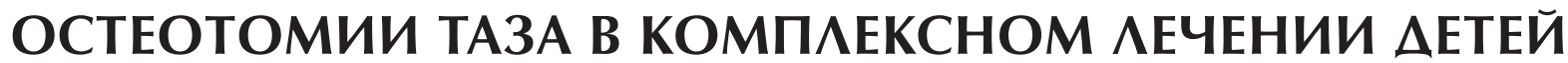 С БОАЕЗНЬЮ АЕГГА - КААЬВЕ — ПЕРТЕСА
}

\author{
(ㄷ Барсуков Д. Б., Камоско М. М. \\ ФГБУ «НИДОИ им. Г. И. Турнера» Минздрава России, Санкт-Петербург
}

В Научно-исследовательском детском ортопедическом институте им. Г. И. Турнера проведен анализ данных обследования 120 пациентов в возрасте от 6 до 14 лет, страдающих болезнью Легга - Кальве - Пертеса с тяжелым поражением эпифиза, с целью улучшения результатов комплексного лечения. Всем пациентам выполнены реконструктивно-восстановительные (ремоделирующие) хирургические вмешательства - корригирующая остеотомия бедра, остеотомия таза по Salter, сочетание этих методик и тройная остеотомия таза, период послеоперационного наблюдения составил в среднем 10 лет. Показано, что остеотомии таза являются операциями выбора при болезни Легга - Кальве - Пертеса наряду с корригирующей остеотомией бедра, а ремоделирование головки бедра возможно только при степени костного покрытия, равной единице или более. Выделены варианты рентгеноанатомического строения пораженного тазобедренного сустава, позволяющие конкретизировать показания к виду хирургического ремоделирования головки бедра.

Ключевые слова: болезнь Пертеса, симптом Дюшена - Тренделенбурга, коксартроз, ремоделирование головки бедренной кости, остеотомия таза.

\section{Введение}

Болезнь Легга - Кальве - Пертеса (БЛКП) относится к числу распространенных заболеваний и составляет $0,17-1,9 \%$ в структуре ортопедической патологии [1-3].

Степень тяжести БЛКП определяется в основном размерами и локализацией очага некроза («секвестра») в эпифизе и возрастом ребенка на момент начала заболевания. Наиболее неблагоприятными в прогностическом плане являются случаи БЛКП с тяжелым (тотальным и субтотальным) поражением эпифиза, когда в очаг некроза вовлекается его латеральный сегмент. Разрушение последнего у детей средней и старшей возрастных групп предопределяет развитие выраженной деформации головки бедра с экструзией из вертлужной впадины. В подобных случаях нередко развивается экструзионный подвывих в тазобедренном суставе. Помимо этого, большие размеры очага некроза обусловливают длительное торпидное течение репаративного процесса. Деформация и экструзия головки бедра становятся в последующем причиной вторичной деформации вертлужной впадины [4-6].

Течение БЛКП с тяжелым поражением эпифиза, за исключением детей младшей возрастной группы, при отсутствии своевременных и адекватных лечебных мероприятий завершается выраженной остаточной деформацией головки бедра и вертлужной впадины. Между тем именно остаточная деформация тазобедренного сустава явля- ется морфологическим субстратом возникновения коксартроза и потому требует профилактики на ранних стадиях заболевания $[3,7,8]$.

Размеры и локализацию потенциального очага некроза, которые во многом определяют лечебную тактику, можно прогнозировать по локализации и протяженности серповидной линии патологического перелома, прослеживающейся в субхондральных отделах эпифиза на рентгенограммах в начале стадии импрессионного перелома [9-12].

Основными задачами лечения детей, страдающих БЛКП с тяжелым поражением эпифиза, являются ремоделирование головки бедра, т. е. восстановление ее формы по форме вертлужной впадины, и предупреждение (или устранение) экструзионного подвывиха в пораженном суставе $[1,13,14]$.

В основе ремоделирования головки бедра лежат некоторые патогенетические особенности БЛКП, в частности: форма вертлужной впадины, как правило, остается нормальной до завершения заболевания; рост покровного хряща головки бедра продолжается, несмотря на наличие очага некроза в эпифизе; отмечается значительная выраженность процессов реваскуляризации очага некроза и новообразования костной ткани $[4,15,16]$. Ремоделирование может проводиться с использованием как консервативных, так и хирургических методов. Необходимыми условиями для его осуществления являются: полное «погружение» 
головки бедра в вертлужную впадину, обеспечивающее степень костного покрытия (СКП), равную единице или более, и устранение компрессии тазобедренного сустава, обусловленной напряжением окружающих мышечных групп $[1,3,9,17]$.

Включение хирургического вмешательства в план комплексного лечения при БЛКП с тяжелым поражением эпифиза у детей средней и старшей возрастных групп способствует более полному восстановлению формы головки бедра, определяющей конгруэнтность суставных поверхностей, и уменьшает продолжительность репаративного процесса. Кроме того, во всех случаях оно обеспечивает стабильность реконструируемого сустава.

Реконструктивно-восстановительными вмешательствами, наиболее часто применяемыми для ремоделирования головки бедра, являются корригирующая остеотомия бедра и остеотомия таза по Salter. Однако при наличии тяжелых анатомических изменений возможно сочетание этих хирургических методик, а также выполнение тройной остеотомии таза $[14,19]$.

Цель исследования: улучшить результаты комплексного лечения детей с БЛКП.

\section{МАТЕРИАА И МЕТОАЫ}

Проанализированы результаты обследования и лечения 120 детей -91 (75,8 \%) мальчика и 29 $(24,2 \%)$ девочек в возрасте от 6 до 14 лет с односторонней БЛКП, характеризующейся тяжелым поражением эпифиза. Из них 90 наблюдений представляют собственный материал, а 30 - apхивный. Комплексное лечение включало одно из вышеупомянутых реконструктивно-восстановительных (ремоделирующих) хирургических вмешательств. На момент операции 56 (46,7 \%) детей находились в возрастной группе 6-8 лет, 40 $(33,7 \%)$ - в группе 9-11 лет и $24(19,6 \%)$ ребенка - в группе 12-14 лет. До госпитализации 92 (76,7 \%) ребенка лечения не получали, а 28 (23,3\%) передвигались при помощи костылей без опоры на «больную» ногу. Для оценки анатомо-функционального состояния пораженного тазобедренного сустава и определения показаний и противопоказаний к операции использовали клинический, рентгенологический и сонографический методы исследования.

Клиническое обследование, проводившееся всем больным в пред- и послеоперационном периодах, позволило определить выраженность ведущих симптомов БЛКП. Походку и симптом Дюшена - Тренделенбурга перед операцией оценивали у 92 больных, которые ранее не получали лечения. Нарушение походки той или иной степени выраженности выявлено у всех обследованных, однако значительное нарушение (хромота) отмечено только при наличии выраженного болевого синдрома - 19 (20,7 \%) случаев. Симптом Дюшена - Тренделенбурга в большинстве случаев - 80 (87\%) больных - был слабоположительным или отрицательным, а у 12 (13\%) больных имел четкую выраженность. Относительное укорочение конечности на стороне поражения в стадии импрессионного перелома в среднем составляло $0,8 \pm 0,3 \mathrm{~cm}$, в стадии фрагментации $-1,7 \pm 1,1$ см, в стадии восстановления $-1,9 \pm 1,2$ см. Ограничение амплитуды отведения и внутренней ротации бедра отмечено у $31(25,8 \%)$ ребенка, внутренней ротации - у 58 (48,3 \%) детей, отведения - у 18 (15\%), при этом болезненность движений бедра в крайних точках амплитуды имелась у 43 (35,8 \%) детей.

Рентгенологическое исследование тазобедренных суставов включало рентгенографию и артрографию. На рентгенограммах в переднезадней проекции и в проекции Лауэнштейна устанавливали размеры и локализацию очага некроза («секвестра») в эпифизе по классификации Catterall или локализацию и протяженность линии субхондрального перелома по классификации Salter - Thomphson, а также стадию заболевания по классификации Рейнберга. Кроме того, при помощи таблицы Шертлайна определяли значения шеечно-диафизарного угла и угла антеторсии шейки бедра.

Распределение больных по стадиям заболевания было следующим: импрессионный перелом диагностирован у 42 (35\%) пациентов, из них 15 (12,5 \%) больных с субхондральным переломом, фрагментация - у 61 (50,8 \%), восстановление у 17 (14,2\%). Определить размеры и локализацию очага некроза в эпифизе можно было только на стадиях импрессионного перелома, исключая случаи субхондрального перелома, и фрагментации, т. е. у 88 (73,3 \%) пациентов. В соответствии с классификацией Catterall у 56 (63,6 \%) детей установлено субтотальное поражение эпифиза (Catterall III), у $32(36,4 \%)$ - тотальное поражение (Catterall IV). В стадии восстановления о тотальном и субтотальном поражении эпифиза свидетельствовала выраженная деформация головки бедра, отмечающаяся только в группах Catterall III и IV. Bce 15 (12,5 \%) больных, имевших в начале стадии импрессионного перелома линию субхондрального патологического перелома в эпифизе, относились к группе Salter - Tomphson B. В последующем у 9 (60\%) из них образовался очаг некроза, соответствующий группе Catterall III, а у $6(40 \%)$ - Catterall IV.

На артрограммах в переднезадней проекции, проекции Лауэнштейна и в аксиальной проекции, 
которые были выполнены 15 (12,5 \%) пациентам, используя костные и хрящевые ориентиры, оценивали пространственное положение тазового и бедренного компонентов сустава, размеры и форму вертлужной впадины и головки бедра, а также соотношения в пораженном суставе. Наиболее важными из изученных рентгенометрических показателей представляются форма хрящевой модели головки бедра на артрограммах в переднезадней проекции и проекции Лауэнштейна и СКП головки бедра на рентгенограмме в переднезадней проекции. Названные показатели отражают как наличие конгруэнтности суставных поверхностей, так и выраженность экструзии головки бедра за пределы впадины, нарушающей стабильность сустава.

Форму хрящевой модели головки бедра определяли по соотношению ее минимального и максимального радиусов при помощи трафарета с концентрическими окружностями, нанесенными на расстоянии 2 мм друг от друга. Трафарет накладывали на артрограмму таким образом, чтобы описанной вокруг контура хрящевой модели оказалась соответствующая окружность минимального диаметра. При значениях данного соотношения более 0,95 хрящевая модель считалась сферичной, при значениях 0,95-0,86 диагностировали I сте- пень деформации, при значениях 0,85-0,76II степень, а при значениях 0,75 и менее - III степень. Выраженная деформация хрящевой модели (II и III степень), имевшая место у большинства детей, преобладала в стадиях фрагментации и восстановления. Сферичная форма головки бедра и умеренная деформация (І степень) встречались в основном в стадии импрессионного перелома.

Степень костного покрытия головки бедра для более точной оценки стабильности сустава определяли в виде десятичной дроби.

Как видно из табл. 1, во всех возрастных группах по мере прогрессирования деформации пораженной головки бедра степень ее костного покрытия постепенно снижалась. Средние значения исследуемого показателя, соответствующие возрастной норме, имели место только при сферичной головке бедра, а наибольшее отклонение от нормальных значений отмечалось при деформациях II и III степени. Сравнение СКП на стороне поражения с таковой в контралатеральном суставе выявило, что ее величина при сферичной головке бедра не отличалась от нормальных значений, при I степени деформации уменьшалась в среднем на 11,3 \%, при II степени - на 23,2 \% и при III степени - на 30,1 \% (рис. 1).

Таблица 1

Показатели СКП в зависимости от возраста ребенка и степени деформации головки белра

\begin{tabular}{|l|c|c|c|c|}
\hline \multirow{2}{*}{$\begin{array}{c}\text { Степень деформации } \\
\text { головки }\end{array}$} & \multicolumn{2}{|c|}{ Возраст больного на момент обследования, лет } & \multirow{2}{*}{ Итого } \\
\cline { 2 - 5 } & $6-8$ & $9-11$ & $12-14$ & $5(4,2)$ \\
\hline Сферичная & $0,85 \pm 0,01$ & $0,89 \pm 0,02$ & - & $20(16,7)$ \\
\hline I & $0,75 \pm 0,01$ & $0,79 \pm 0,01$ & $0,68 \pm 0,03$ & $49(40,8)$ \\
\hline II & $0,64 \pm 0,01$ & $0,67 \pm 0,02$ & $0,61 \pm 0,01$ & $46(38,3)$ \\
\hline III & $0,57 \pm 0,02$ & $0,60 \pm 0,01$ & 24 & $120(100)$ \\
\hline Всего ... & 56 & 40 & - & \\
\hline
\end{tabular}

Примечание. В скобках указан процент.

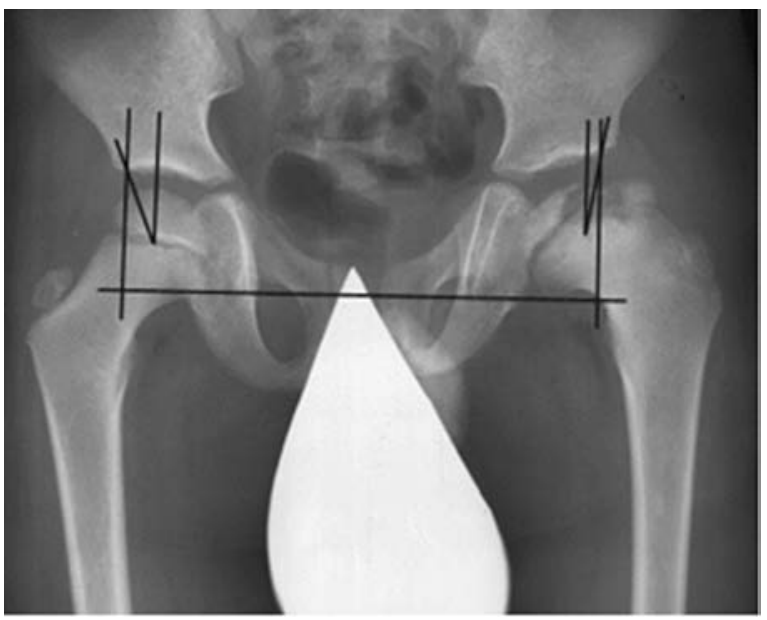

$a$

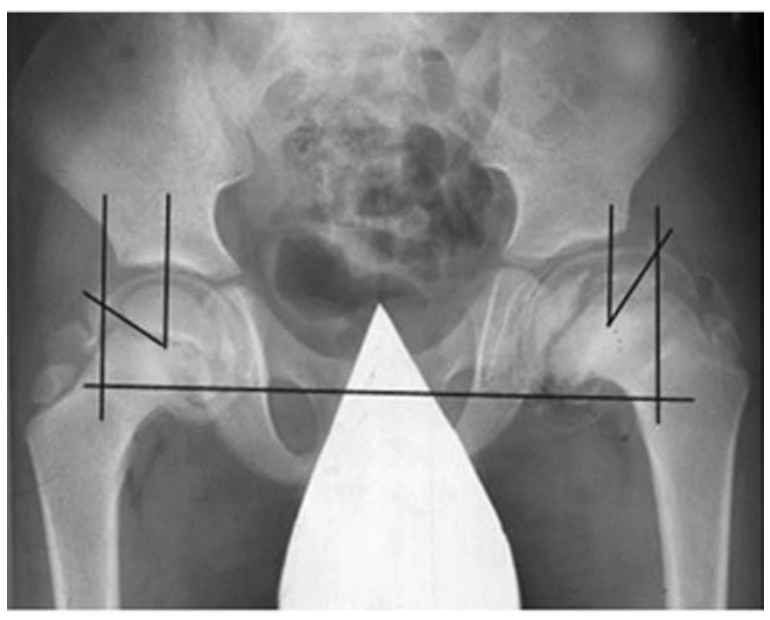

6

Рис. 1. Рентгенограмма (a) и артрограмма (б) больного А. 6 лет. Диагноз: Болезнь Легга - Кальве - Пертеса в стадии фрагментации с субтотальным поражением эпифиза слева. Отмечается снижение степени костного и хрящевого покрытия и уменьшение угла Виберга, измеренного по костным и хрящевым ориентирам 
При выборе оптимального метода хирургического вмешательства одними из наиболее важных показателей являлись пространственное положение большого вертела относительно головки бедра на рентгенограмме в переднезадней проекции и значение угла антеторсии шейки бедра. Пространственное положение большого вертела оценивали по соотношению его вершины и точки «О», которая у детей в возрасте 9 лет и старше совпадает с центром головки бедра (рис. $2, a$ ), а у детей 6-8 лет находится на границе верхней и средней трети радиуса головки бедра, соединяющего центр и нижний полюс (рис. 2, б). Последние определяли по трафарету с концентрическими окружностями.

На функциональной артрограмме за счет отведения и (или) внутренней ротации бедра моделировали положение вершины большого вертела (ВБВ) на уровне точки «О» при фронтальном положении шейки бедра. Однако если на рентгенограмме в переднезадней проекции ВБВ находилась на уровне точки «О» или выше, то на функциональной артрограмме такое положение не изменялось.

В результате проведенного рентгенологического обследования 120 больных выделено 11 вариантов рентгеноанатомических нарушений в пораженном суставе, отличающихся пространственным положением большого вертела и шейки бедра, а также степенью костного покрытия головки бедра (табл. 2). На функциональной артрограмме у 2 детей с деформацией хрящевой модели головки бедра III степени отмечался феномен hinge-abduction ${ }^{1}$, не позволивший определить рентгеноанатомический вариант непосредственно при выполнении артрографии.

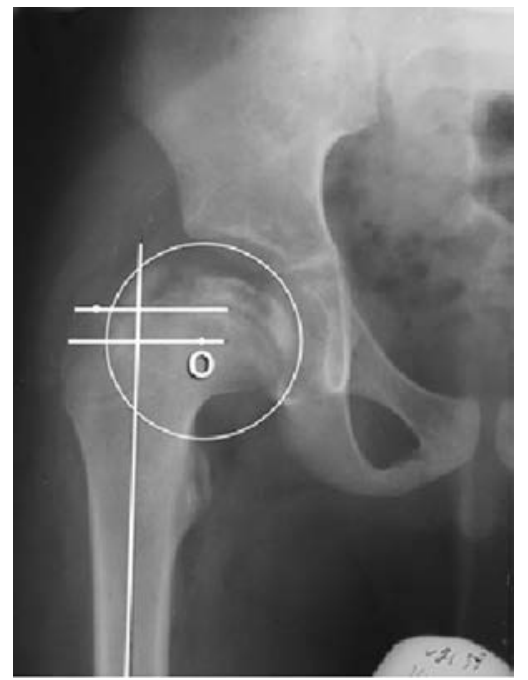

$a$
Сонографическое исследование, проведенное 58 больным до операции, позволило определить выраженность воспалительного процесса в пораженном суставе. Избыточное количество суставной жидкости отмечено у $14(24,1 \%)$ больных с импрессионным переломом. Выраженность сонографических проявлений синовита в последующих стадиях заболевания оказалась незначительной.

Показаниями к хирургическому ремоделированию головки бедра с использованием реконструктивно-восстановительных вмешательств при БЛКП у детей в возрасте 6 лет и старше являлись: стадия импрессионного (субхондрального) перелома с линией субхондрального перелома, соответствующей Salter - Tomphson В; стадии импрессионного перелома и фрагментации с очагами некроза, соответствующими Catterall III и IV; стадия восстановления с деформацией хрящевой модели головки бедра III степени, нарушающей стабильность сустава.

Противопоказаниями к операции являлись: стадия остеонекроза; стадия импрессионного (субхондрального) перелома с линией субхондрального перелома, соответствующей Salter - Tomphson A; стадии импрессионного перелома и фрагментации с очагами некроза, соответствующими Catterall I и II; стадия восстановления с деформацией хрящевой модели головки бедра I и II степени, не нарушающей стабильность сустава; стадия исхода.

Помимо этого, при наличии клинико-сонографической картины сопутствующего синовита оперативное вмешательство откладывали до подавления воспалительных явлений в пораженном суставе.

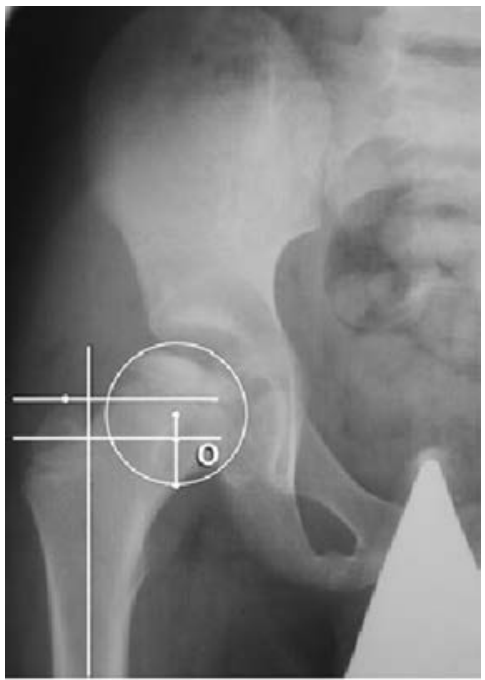

6

Рис. 2. Методика определения пространственного положения большого вертела относительно головки бедра

1 Феномен hinge-abduction имеет место в случаях выраженной деформации головки бедра, верхний полюс которой при отведении в тазобедренном суставе не погружается в вертлужную впадину, а отталкивается от ее края, что приводит к латеропозиции нижнего полюса. Погружению головки бедра препятствует натяжение суставной капсулы, блокирующей нижние отделы вертлужной впадины. 
В работе придерживались общих принципов хирургического лечения детей с БЛКП: однократность вмешательства на тазобедренном суставе; выбор операции наименьшего объема, обеспечивающей СКП, равную единице, и исключающей выраженную деформацию тазового и бедренно- го компонентов сустава; возможно более ранние сроки проведения вмешательства.

Выбор оптимального метода хирургического вмешательства определялся вариантом рентгеноанатомических нарушений в пораженном суставе и возрастом больного (табл. 3).

таблица 2

Варианты рентгеноанатомических нарушений в тазобедренном суставе у детей при БАКП с тяжелым поражением эпиориза

\begin{tabular}{|c|c|c|c|c|c|}
\hline \multirow[b]{2}{*}{$\begin{array}{c}\text { № } \\
\text { вариан- } \\
\text { та }\end{array}$} & \multicolumn{3}{|c|}{ Рентгеноанатомические признаки } & \multirow[b]{2}{*}{$\begin{array}{l}\text { Наименование } \\
\text { функциональной } \\
\text { артрограммы }\end{array}$} & \multirow[b]{2}{*}{$\begin{array}{l}\text { Всего } \\
\text { боль- } \\
\text { ных }\end{array}$} \\
\hline & $\begin{array}{c}\text { положение ВБВ } \\
\text { и СКП на рентгенограмме } \\
\text { в переднезадней проекции }\end{array}$ & $\begin{array}{c}\text { истинный } \\
\text { угол } \\
\text { антеторсии }\end{array}$ & $\begin{array}{c}\text { СКП на } \\
\text { функциональной } \\
\text { артрограмме }\end{array}$ & & \\
\hline 1 & $\begin{array}{l}\text { ВБВ на уровне или выше точ- } \\
\text { ки «О», СКП } \geq 2 / 3\end{array}$ & $>5^{\circ}$ & $\geq 1$ & $\begin{array}{c}\text { C внутренней ротацией } \\
\text { бедра }\end{array}$ & 10 \\
\hline 2 & $\begin{array}{l}\text { ВБВ на уровне или выше точ- } \\
\text { ки «О», СКП } \geq 2 / 3\end{array}$ & $>5^{\circ}$ & $<1$ & То же & 14 \\
\hline 3 & $\begin{array}{l}\text { ВБВ на уровне или выше точ- } \\
\text { ки «О», СКП < } 2 / 3\end{array}$ & $>5^{\circ}$ & $<1$ & То же & 12 \\
\hline 4 & $\begin{array}{l}\text { ВБВ ниже точки «О», } \\
\text { СКП } \geq 2 / 3\end{array}$ & $\leq 5^{\circ}$ & $\geq 1$ & С отведением бедра & 10 \\
\hline 5 & ВБВ ниже точки «О», СКП $\geq 2 / 3$ & $\leq 5^{\circ}$ & $<1$ & То же & 13 \\
\hline 6 & ВБВ ниже точки «О», СКП $<2 / 3$ & $\leq 5^{\circ}$ & $<1$ & То же & 12 \\
\hline 7 & $\begin{array}{l}\text { ВБВ ниже точки «О», } \\
\text { СКП } \geq 2 / 3\end{array}$ & $>5^{\circ}$ & $\geq 1$ & $\begin{array}{c}\text { С отведением и внутрен- } \\
\text { ней ротацией бедра }\end{array}$ & 10 \\
\hline 8 & ВБВ ниже точки «О», СКП $\geq 2 / 3$ & $>5^{\circ}$ & $<1$ & То же & 13 \\
\hline 9 & ВБВ ниже точки «О», СКП < 2/3 & $>5^{\circ}$ & $<1$ & То же & 12 \\
\hline 10 & $\begin{array}{l}\text { ВБВ на уровне или выше точ- } \\
\text { ки «О», СКП } \geq 2 / 3\end{array}$ & $\leq 5^{\circ}$ & - & Не выполняется & 9 \\
\hline 11 & $\begin{array}{l}\text { ВБВ на уровне или выше точ- } \\
\text { ки «О», СКП }<2 / 3\end{array}$ & $\leq 5^{\circ}$ & - & Не выполняется & 5 \\
\hline Всего ... & & & & & 120 \\
\hline
\end{tabular}

Таблица 3

Показания к реконструктивно-восстановительным (ремоделирующим) хирургическим вмешательствам при БАКП с тяжелым поражением эпифиза

\begin{tabular}{|c|c|c|c|c|}
\hline \multirow[b]{2}{*}{ Метод лечения } & \multicolumn{2}{|l|}{ Показания } & \multirow{2}{*}{$\begin{array}{c}\text { Количество } \\
\text { операций }\end{array}$} & \multirow[b]{2}{*}{ Итогс } \\
\hline & $\begin{array}{l}\text { вариант рентгено-анато- } \\
\text { мических нарушений }\end{array}$ & $\begin{array}{l}\text { возраст, } \\
\text { лет }\end{array}$ & & \\
\hline $\begin{array}{l}\text { Корригирующая (деторсионная) остеото- } \\
\text { мия бедра }\end{array}$ & 1 & $6-14$ & 10 & \multirow[t]{3}{*}{30} \\
\hline $\begin{array}{l}\text { Корригирующая (варизирующая) остео- } \\
\text { томия бедра }\end{array}$ & 4 & $6-14$ & 10 & \\
\hline $\begin{array}{l}\text { Корригирующая (деторсионно-варизиру- } \\
\text { ющая) остеотомия бедра }\end{array}$ & 7 & $6-14$ & 10 & \\
\hline Остеотомия таза по Salter & $2,5,8,10$ & $6-8$ & 30 & 30 \\
\hline $\begin{array}{l}\text { Остеотомия таза по Salter с корригирую- } \\
\text { щей (деторсионной) остеотомией бедра }\end{array}$ & 3 & $6-8$ & 5 & \multirow[t]{3}{*}{15} \\
\hline $\begin{array}{l}\text { Остеотомия таза по Salter с корригирую- } \\
\text { щей (варизирующей) остеотомией бедра }\end{array}$ & 6 & $6-8$ & 5 & \\
\hline $\begin{array}{l}\text { Остеотомия таза по Salter с корригирую- } \\
\text { щей (деторсионно-варизирующей) остео- } \\
\text { томией бедра }\end{array}$ & 9 & $6-8$ & 5 & \\
\hline \multirow[t]{2}{*}{ Тройная остеотомия таза } & $2,3,5,6,8,9,10$ & $9-14$ & 10 & \multirow[t]{2}{*}{15} \\
\hline & 11 & $6-14$ & 5 & \\
\hline Всего ... & & & 90 & 90 \\
\hline
\end{tabular}


Остеотомию таза по Salter выполняли в модификации И. Ю. Поздникина ${ }^{1}$, позволяющей не допустить низведение ацетабулярного фрагмента тазовой кости во время его ротации кпереди и отличающейся стабильной фиксацией последнего в положении коррекции без использования трансплантата. Характерной особенностью предложенной методики является сечение тела подвздошной кости в плоскости, близкой к сагиттальной, при этом наружный кортикальный слой пересекается практически по линии прикрепления суставной капсулы, а внутренний - несколько выше. Ротация ацетабулярного фрагмента без низведения позволяет избежать дополнительной компрессии пораженного сустава, что особенно важно именно при БЛКП. Для декомпрессии выполнялась тенотомия пояснично-подвздошной мышцы.

При выполнении остеотомии таза по Salter в сочетании с корригирующей остеотомией бедра надвертлужное сечение подвздошной кости было горизонтальным с закруглением книзу в передней четверти, а для фиксации ацетабулярного фрагмента использовался цилиндрический трансплантат, заимствованный из дистального фрагмента бедренной кости. Корригирующую остеотомию бедра производили на межвертельном уровне, при этом в случае варизации остеотомия была косой, вершину большого вертела устанавливали на уровне точки «О», а в случае деторсии остеотомия была поперечной, угол антеторсии уменьшали до $5^{\circ}$. Дистальный фрагмент бедренной кости во всех случаях медиализировался на одну треть своего диаметра.

Тройная остеотомия таза предусматривала параацетабулярное сечение костей, исключающее значительную деформацию таза. Надвертлужное сечение подвздошной кости соответствовало таковому при остеотомии таза по Salter в сочетании с корригирующей остеотомией бедра, седалищная кость пересекалась поперечно выше седалищного бугра, а лонная кость - косо у латерального края запирательного отверстия. Ротация ацетабулярного фрагмента кпереди и наклон кнаружи сочетались с медиализацией его нижнего полюса.

\section{РЕЗУАЬТАТЫ}

Результаты лечения оценивали через 5, 10 и 15 лет после операции в 4 группах больных (90 детей) в зависимости от метода хирургического вмешательства и СКП головки бедра непосредственно после завершения последнего. 1-я группа $(n=30)$ - остеотомия таза по Salter, СКП $\geqslant 1 ; 2$-я группа $(n=15)-$ остеотомия таза по Salter с корригирующей остеотомией бедра, СКП $\geqslant 1 ; 3$-я группа $(n=15)$ - тройная остеотомия таза, СКП $\geqslant 1 ; 4$-я группа $(n=30)-$ корригирующая остеотомия бедра с СКП $<1$.

В первых трех группах имело место улучшение клинико-рентгенологической картины, в том числе формы головки бедра, независимо от использованного хирургического метода. В 4-й группе, представленной архивным материалом (больные, оперированные до 1998 г.), отмечалось клинико-рентгенологическое ухудшение с выраженной остаточной деформацией головки бедра. Наиболее показательным представляется сравнение результатов лечения больных 4-й группы и 40 больных 1,2 и 3-й групп, которые имели $2,3,5,6,8$ и 9-й варианты рентгеноанатомических нарушений. До 1998 г. детям с указанными рентгеноанатомическими вариантами выполнялась корригирующая остеотомия бедра, а в последующем - остеотомия таза как самостоятельное вмешательство или в сочетании с корригирующей остеотомией бедра. Такое изменение хирургической тактики потребовалось в связи с тем, что при рассматриваемых вариантах строения пораженного сустава корригирующая остеотомия бедра не обеспечивала полное «погружение» головки бедра в вертлужную впадину (СКП = 1).

При обследовании через 10 лет после операции в 4-й группе рентгенологически артротические изменения в виде склерозирования субхондральных отделов вертлужной впадины и головки бедра, особенно выраженного в очаге гиперпрессии, образовавшемся под влиянием секущей нагрузки ацетабулярного края, имели место у 20 $(66,7$ \%) больных. В дальнейшем у больных отмечались типичные признаки деформирующего коксартроза. При этом у 36 (90 \%) больных 1, 2 и 3-й групп в структуре костной ткани головки и шейки бедра отсутствовали видимые нарушения, рентгеновская суставная щель сохраняла одинаковую высоту на всем протяжении. Форма головки бедра и показатели стабильности сустава (СКП, углы вертикального и горизонтального соответствия, угол Виберга) у больных 1, 2 и 3-й групп находились в пределах нормы или приближались к ней, в то время как у больных 4-й группы прогрессивно ухудшались.

В 1, 2 и 3-й группах количество больных со сферичной головкой бедра увеличилось на $12,5 \%$ и составило 7 (17,5\%), с деформацией I степе-

1 Поздникин И. Ю. Способ хирургического лечения патологии тазобедренного сустава. Изобретения. Полезные модели. 2004; 21, ч. 2: 263.

- Ортопедия, травматология и восстановительная хирургия Аетского возраста. Том II. 


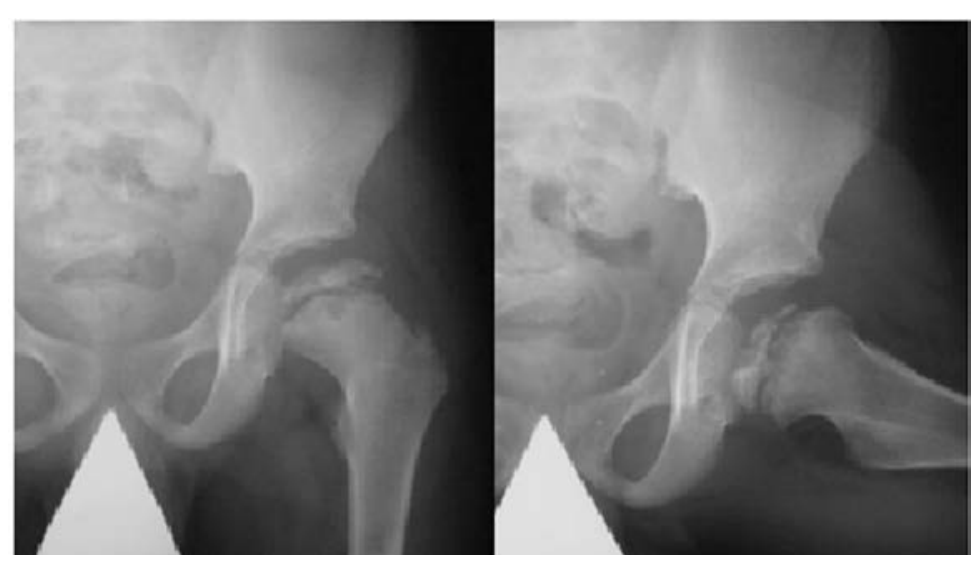

$a$

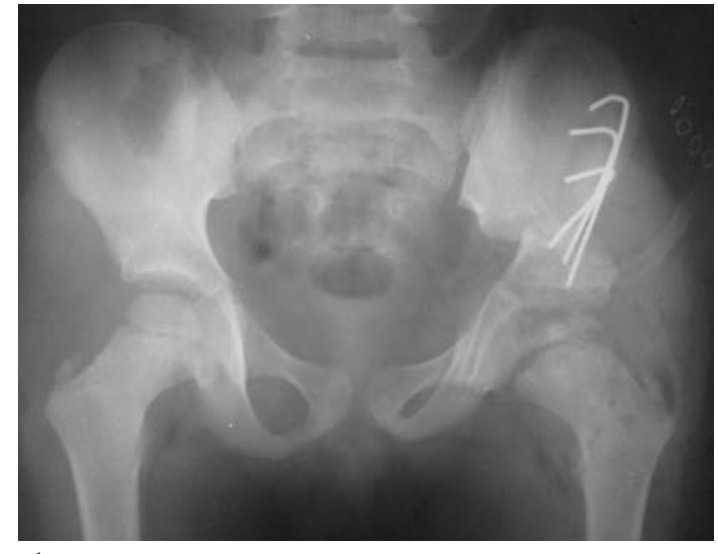

6

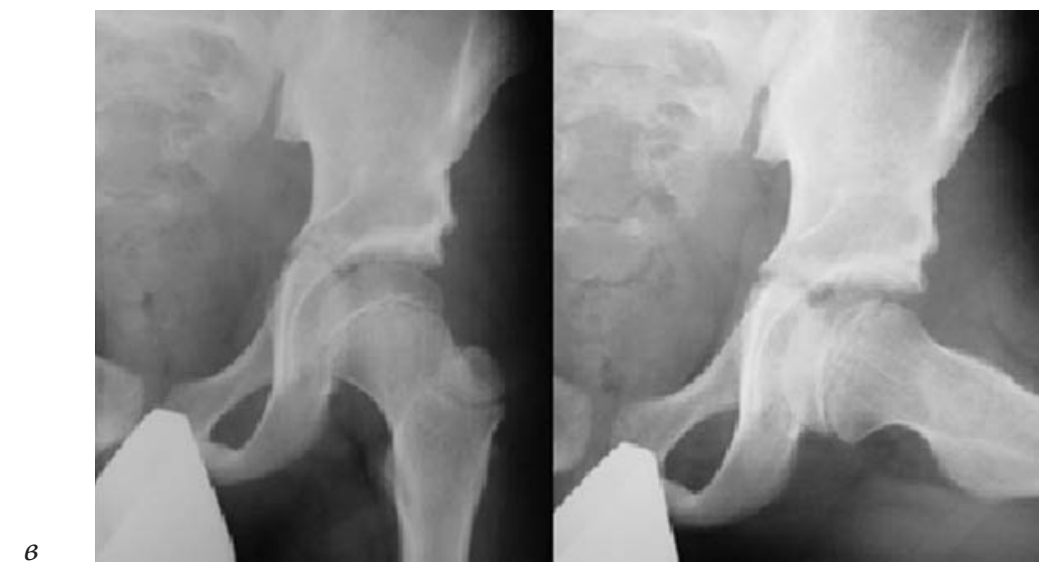

Рис. 3. Рентгенограммы больного Л. 6,5 года. Диагноз: болезнь Легга - Кальве - Пертеса в стадии фрагментации с тотальным поражением эпифиза слева. $a-$ до операции; $6-$ на операционном столе; $8-$ через 6 лет после операции
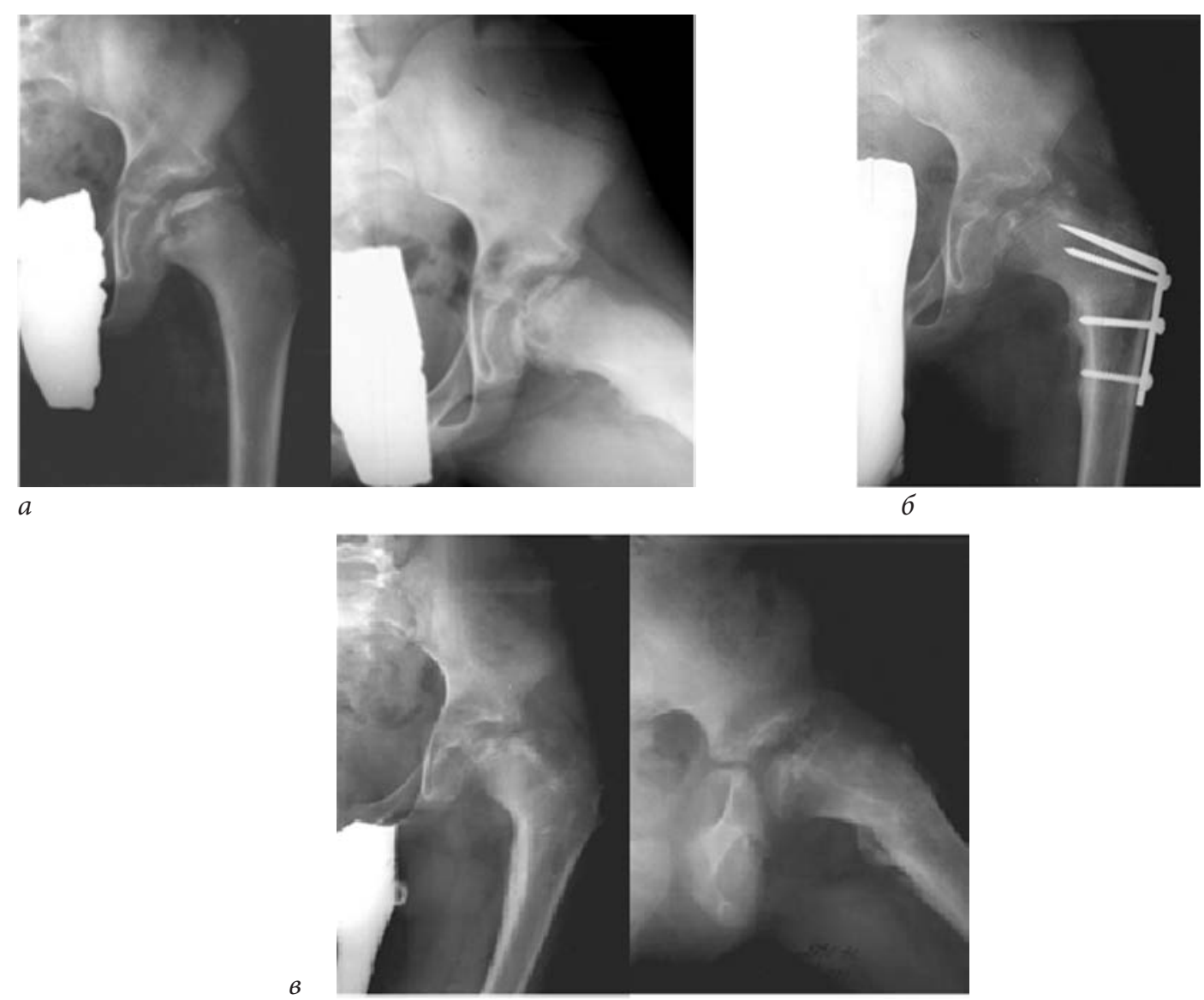

Рис. 4. Рентгенограммы больного 3., 10 лет. Диагноз: болезнь Легга - Кальве - Пертеса в стадии фрагментации с тотальным поражением эпифиза слева. $a-$ до операции; 6 - через 6 мес. после операции; 8 - через 2 года после операции 
ни увеличилось на 32,5 \% и составило 20 (50\%), тогда как с деформацией II степени уменьшилось на 17,5 \% и составило 10 (25\%), а с деформацией III степени уменьшилось на 27,5 \% и составило 3 (7,5 \%) по сравнению с результатами предоперационного обследования (рис. 3). В 4-й группе количество больных с деформацией головки бедра II степени уменьшилось на 16,6 \% и составило 5 (16,7 \%), а с деформацией III степени, напротив, увеличилось на 23,3 \% и составило 25 (83,3\%), больных с деформацией I степени и сферичной головкой бедра не выявлено (рис. 4).

Клинически у 14 (46,7 \%) больных 4-й группы имела место выраженная хромота и болезненность движений, у 15 (50 \%) отмечался положительный симптом Дюшена - Тренделенбурга. В дальнейшем количество неудовлетворительных результатов лечения в этой группе больных увеличилось. Между тем в 1, 2 и 3-й группах нарушение походки выявлено только у 5 (12,5\%) больных, причем выраженной хромоты и болезненности движений в указанных случаях не отмечалось. Симптом Дюшена - Тренделенбурга у 9 (22,5 \%) пациентов был слабоположительным.

В отдаленном периоде наблюдения 3 больным со 2-м и 11-м вариантами рентгеноанатомических нарушений из 1-й и 3-й групп потребовалось низведение большого вертела в связи с высоким стоянием последнего. В период течения БЛКП у этих детей отмечалось положение вершины большого вертела выше точки «О», что является не часто встречающейся анатомической особенностью.

\section{ВывОАЫ}

1. Остеотомия таза по Salter, остеотомия таза по Salter в сочетании с корригирующей остеотомией бедра и тройная остеотомия таза являются операциями выбора при БЛКП наряду с корригирующей остеотомией бедра, поскольку они способствуют ремоделированию головки бедра и предупреждению (или устранению) экструзионного подвывиха. Выделенные варианты рентгеноанатомического строения пораженного сустава позволяют конкретизировать показания к остеотомиям таза.

2. Форма головки бедра при БЛКП с тяжелым поражением эпифиза зависит не столько от метода хирургического вмешательства, сколько от величины СКП, полученной в ходе последнего. Ремоделирование головки бедра возможно только при создании в ходе операции СКП $\geq 1$, а при СКП < 1 отмечается прогрессирование деформации.

3. Остеотомии таза, ввиду относительно большого объема вмешательства, следует использовать при БЛКП только в тех анатомических ситуациях, когда противопоказана корригирующая остеотомия бедра.

\section{Аитература}

1. Барсуков Д. Б. Ортопедо-хирургическое лечение детей с болезнью Легга - Кальве - Пертеса: Дис. ... канд. мед. наук; СПб; 2003.

2. Веселовский Ю.А., Тихоненков Е.С., Садофьева В. И. Идиопатический асептический некроз головки бедренной кости у детей: Методические рекомендации. Л.; 1989.

3. Schultz K., Dustmann H. Morbus Perthes. Berlin: Springer; 1992.

4. Catterall A. Legg-Calve-Perthes syndrome. Clin. Orthop. Relat. Res. 1981; (158): 41-52.

5. Catterall A. Natural history, classification and X-ray signs in Legg-Calve-Perthes' disease. Acta Orthop. Belg. 1980; 46 (4): 346-51.

6. Tannast M. Hanke M., Ecker T.M., Murphy S.B., Albers C.E., Puls M. LCPD: reduced range of motion resulting from extra- and intraarticular impingement. Clin. Orthop. Relat. Res. 2012; 470 (9): 2431-40.

7. Ganz R., Leunig M., Leunig-Ganz K., Harris W. H. The etiology of osteoarthritis of the hip: an integrated mechanical concept. Clin. Orthop. Relat. Res. 2008; 466 (20): 264-72.

8. Shore B. J. Novais E.N., Millis M.B., Kim Y. J. Low early failure rates using a surgical dislocation approach in healed Legg-Calvé-Perthes disease. Clin. Orthop. Relat. Res. 2012; 470 (9): 2441-9.

9. Salter R. B. Legg-Perthes disease: the scientific basis for the methods of treatment and their indications. Clin. Orthop. 1980; (150): 8-11.

10. Кузнечихин Е.П., Моисеев С. Н. Остеохондропатия головки бедренной кости (диагностика и принципы лечения, предупреждающие развитие коксартроза и инвалидности у детей). Пособие для врачей. М.: РГМУ; 1997.

11. Марков И. В. Прогнозирование течения болезни Легга - Кальве - Пертеса и выбор тактики лечения: Автореф. дис. ... канд. мед. наук. Курган, 2012.

12. Salter R. B., Thompson G. H. Legg-Calve-Perthes Disease. The prognostic significance of the subchondral fracture and a two-group classification of the femoral head involvement. J. Bone Jt. Surg. Am. 1984; 66 (4):479-89.

13. Klisić P. J. Treatment of Perthes' disease in older children. J. Bone Jt Surg. Br. 1983; 65 (4): 419-27.

14. Thompson G. H. Salter osteotomy in Legg-CalvéPerthes disease. J. Pediatr. Orthop. 2011; 31 (2 Suppl): 192-7.

15. Joseph B. Morphological changes in the acetabulum in Perthes' disease. J. Bone Jt Surg. Br. 1989; 71 (5): 756-63. 
16. Mose K. Methods of measuring in Legg-Calve-Perthes diasease with special regard to the prognosis. Clin. Orthop. 1980; (150):103-9.

17. Thompson G.H., Salter R. B. Legg-Calve-Perthes disease. Clin. Symp. 1986; 38 (1): 2-31 .

18. Деменцов А. Б. Тройная остеотомия таза при неблагоприятном течении болезни Легга - Кальве - Пертеса: Автореф. дис. ... канд. мед. наук; Минск; 2011.
19. Wenger D. R. Pring M.E., Hosalkar H.S., Caltoum C.B., Lalonde F.D., Bastrom T. P. Advanced containment methods for Legg-Calvé-Perthes disease: results of triple pelvic osteotomy. J. Pediatr. Orthop. 2010; 30 (8): 749-57.

\title{
PELVIC OSTEOTOMY IN THE COMPLEX TREATMENT OF CHILDREN WITH LEGG-CALVE-PERTHES DISEASE
}

\author{
Barsukov D. B., Kamosko M. M.
}

FSBI “Scientific and Research Institute for Children's Orthopedics n. a. G. I. Turner" under the Ministry of Health of the Russian Federation

$\diamond \quad$ At the Scientific and Research Institute for Children's Orthopedics n. a. G. I. Turner we analyzed survey data of 120 patients aged from 6 to 14 years old with Legg-Calve-Perthes disease with severe epiphysis deformation, in order to improve the outcomes. All patients underwent reconstructive (remodeling) surgery - a corrective hip osteotomy, a pelvic osteotomy by Salter, a combination of these techniques and a triple pelvic osteotomy. Postoperative followup period averaged 10 years. It is shown that pelvic osteotomy is an operation of choice for Legg-Calve-
Perthes disease along with corrective hip osteotomy, and remodeling of the femoral head is only possible when the degree of bone coverage is equal to one or more. We highlighted radioanatomical structure of the affected hip joint, allowing to precise indications for surgical remodeling type of femoral head.

$\diamond$ Keywords: Legg-Calve-Perthes disease, DuchenneTrendelenburg syndrome, coxarthrosis, femoral head remodeling, pelvic osteotomy.
Барсуков Дмитрий Борисович - к. м. н., научный сотрудник отделения патологии тазобедренного сустава ФГБУ «НИДОИ им. Г. И. Турнера» Минздрава России. 196603, СПб, г. Пушкин, ул. Парковая, д. 64-68. E-mail: dbbarsukov@gmail.com

Камоско Михаил Михайлович - д. м. н., руководитель отделения патологии тазобедренного сустава ФГБУ «НИДОИ им. Г. И. Турнера» Минздрава России. 196603, СПб, г. Пушкин, ул. Парковая, д. 64-68. E-mail: mkamosko@gmail.com
Barsukov Dmitry Borisovich - $\mathrm{MD}, \mathrm{PhD}$, research associate of the department of hip pathology. FSBI "Scientific and Research Institute for Children's Orthopedics n. a. G. I. Turner" under the Ministry of Health of the Russian Federation. 196603, Saint-Petersburg, Pushkin, Parkovaya str., 64-68. E-mail: dbbarsukov@gmail.com

Kamosko Mikhail Mikhailovich - MD, PhD, DMedSc, head of the department of hip pathology. FSBI "Scientific and Research Institute for Children's Orthopedics n. a. G. I. Turner" under the Ministry of Health of the Russian Federation. 196603, Saint-Petersburg, Pushkin, Parkovaya str., 64-68. E-mail: mkamosko@gmail.com 